\title{
Parameter Estimation of Structural Equation Modeling Using Bayesian Approach
}

\author{
Dewi Kurnia Sari, Ni Wayan Surya Wardhani, Suci Astutik \\ Department of Statistics, Faculty of Mathematics and Natural Sciences \\ Brawijaya University, Malang
}

Email: dewi.kurnia.14@gmail.com

\begin{abstract}
Leadership is a process of influencing, directing or giving an example of employees in order to achieve the objectives of the organization and is a key element in the effectiveness of the organization. In addition to the style of leadership, the success of an organization or company in achieving its objectives can also be influenced by the commitment of the organization. Where organizational commitment is a commitment created by each individual for the betterment of the organization. The purpose of this research is to obtain a model of leadership style and organizational commitment to job satisfaction and employee performance, and determine the factors that influence job satisfaction and employee performance using SEM with Bayesian approach. This research was conducted at Statistics FNI employees in Malang, with 15 people. The result of this study showed that the measurement model, all significant indicators measure each latent variable. Meanwhile in the structural model, it was concluded there are a significant difference between the variables of Leadership Style and Organizational Commitment toward Job Satisfaction directly as well as a significant difference between Job Satisfaction on Employee Performance. As for the influence of Leadership Style and variable Organizational Commitment on Employee Performance directly declared insignificant.
\end{abstract}

Keywords: SEM, Bayesian, Leadership Style, Organizational Commitment, Job Satisfaction, Employee Performance.

\section{INTRODUCTION}

Leadership is a process of influencing, directing and giving examples of his subordinates in order to achieve organizational goals. Every leader must have style, personality traits, habits, character and personality are different. Leadership is a key element in an organization's effectiveness [1]. Based on this, it can be said that the role of a leader is very important for achieving the vision, mission and goals of an organization. Moreover, the success of an organization or company in achieving its objectives can be influenced also by the commitment of the organization. Where organizational commitment is a commitment made by each individual to the organization's progress. The commitment is visible when individuals can exercise their rights and obligations in accordance with the duties and functions of each organization. Therefore, an organization must give your full attention and make employees believe the organization, so it will obtain high organizational commitment.

Many ways to measure the impact of leadership style and organizational commitment to employee performance, one of which is the structural equation modeling is a multivariate analysis 
technique that combines the measurement model as in the confirmatory factor analysis with structural model on regression analysis or analysis of lines. One of the assumptions that must be met in the SEM is the sample size should be large enough. Other assumptions that must be met is an indicator to follow a multivariate normal distribution and the indicator variables with latent variables and between latent variables have a linear relationship. The use of small sample size in a SEM with a classical approach can generate sample covariance matrix is singular.

If the requirements analysis Structural Equation Modeling (SEM) is not fulfilled such a small sample size, it would require alternative methods to resolve the issue is through a Bayesian approach. Some of the advantages include: (1) Bayesian methods more emphasis on the use of individual data rather than sample covariance matrix, (2) latent variable can be predicted directly (3) using prior information. Other virtues are not taking into account the size of the sample that will affect the operating costs of research.

This study was conducted to determine the effect of leadership style and organizational commitment to job satisfaction and employee performance in the FNI Statistics using Structural Equation Modeling (SEM) through a Bayesian approach.

\section{THEORITICAL REVIEW}

\section{Basic Concepts SEM analysis with Bayesian Approach}

Analysis of the relationship between latent variables need to be developed so that the resulting model to be more precise, especially for complex problems. One method of analysis that is often used to test whether there is influence between the latent variable is the analysis of Structural Equation Modeling (SEM). One of the assumptions that must be fulfilled in such method is the sample size should be large enough. According to [2] suggested sample size to use Maximum Likelihood Estimation (MLE) is approximately 100-200 or be greater when using asymptotically approaches Distribution Free (ADF) to handle the data distribution is not normal.

The classical method in the analysis of SEM depends on the matrix variance covariance sample $S$ and not on the response variable vector. The structure of matrix $\Sigma(\theta)$ is the variance covariance matrix containing the parameter $\theta$ with large dimensions. Estimation of $\theta$ by minimizing some objective function to calculate $\Sigma(\theta)$ Estimation methods commonly used in standard SEM is the maximum likelihood estimation (MLE) or generalized least squares (GLS). Analysis of variance covariance based heavily dependent on the asymptotic normality of the matrix S. Using a small sample in SEM with a classical approach can produce a negative variance [3] as well as the sample covariance matrix is singular [4]. In addition, the use of MLE when the small sample size could lead to biased results of estimation parameters [3]. Based on this, we need an alternative method to solve the problem of small sample size, namely through a Bayesian approach. Development of Bayesian SEM is intended to allow estimation of the model can be done even if some assumptions are not met.

SEM testing method with the Bayesian approach is not based on the variance covariance matrix but based on the number of individual data (observations). In SEM with maximum likelihood approach, $\theta$ is not considered as a random variable where $\theta$ is $\Phi, \Psi, \Lambda, \Gamma, B$. While the Bayesian approach SEM, $\theta$ is considered as a random variable that has a distribution. Furthermore, the distribution referred to as the prior distribution. If $M$ is a SEM equation with vector parameter $\theta$ is unknown, the density function chances of $\theta$ is $p(\theta \mid M)$. If the Bayesian inference is based on data observations $\mathrm{Y}$ then the joint distribution of $\mathrm{Y}$ and $\theta$ on $\mathrm{M}$ is $p(\mathrm{Y}, \theta \mid M)$. With

$$
p(\mathrm{Y}, \theta \mid M)=p(Y \mid \theta, M) p(\theta)=p(\theta \mid \mathrm{Y}, M) p(\mathrm{Y} \mid M)
$$

and that $p(\mathrm{Y} \mid M)$ does not depend on $\theta$ and with regard $\mathrm{Y}$ has been determined and constant, then:

where,

$$
\log p(\theta \mid \mathrm{Y}, M) \propto \log p(\mathrm{Y} \mid \theta, M)+\log p(\theta)
$$

$M \quad$ : any form of SEM with a vector parameter $\theta$ is unknown

Y : Data observations of size $\mathrm{n}$

$p(\theta \mid M) \quad$ : prior distribution of $\theta$ in $M$ model

$p(\mathrm{Y}, \theta \mid M)$ : probability join distribution from $\mathrm{Y}$ and $\theta$ with $M$ model is known, 
$p(\theta \mid \mathrm{Y}, M) \quad$ : probability distribution from posterior

$p(\mathrm{Y} \mid \theta, M)$ : likelihood function

In equation (2.2) $p(\mathrm{Y} \mid \theta, M)$ is influenced by the number of instances while $\mathrm{p}(\theta)$ is not. For a large number of examples of the $\log p(\mathrm{Y} \mid \theta, M)$ will dominate $\log p(\theta)$, so it has little prior and posterior density function will be approaching the log-likelihood function of $p(\mathrm{Y} \mid \theta, M)$. On the contrary, for a small sample, prior distribution of $\theta$ has a significant role.

\section{Prior Distribution}

Prior was the initial information parameter values in the model. Basically there are two types of prior distribution is non-informative prior distribution and the distribution of informative priors.

For example, $Y=\left(y_{1}, \ldots, y_{n}\right)$ is the matrix of the data observation and $\Omega=\left(\omega_{1}, \ldots, \omega_{n}\right)$ is the matrix of factor score of latent variable and $\theta$ is the structure of vector parameter which cover unknown element of $\Lambda, \Psi_{\varepsilon}, \Pi, \Gamma, \Phi, \Psi_{\delta}$. In posterior analysis, data observations $Y$ was added with matrix of latent variable $\Omega$ and the joint posterior distribution $[\theta, \Omega \mid Y]$. To derive the formula $\mathrm{p}[\theta \mid \Omega, \mathrm{Y}]$, is required prior to the distribution of the components $\theta$ and Lee (2007) using a type of conjugate prior distribution. $\Lambda_{k}^{T}$ is row of-k $\Lambda$ so that conjugate prior distribution from $\left(\Lambda_{\mathrm{k}}, \psi_{\mathrm{ek}}\right)$ are as follows:

or equivalent with

$$
\psi_{e k} \stackrel{D}{\Rightarrow} \text { InvertedGamma }\left(\alpha^{*}{ }_{0 e k}, \beta^{*}{ }_{0 e k}\right)
$$

and

$$
\psi_{e k} \stackrel{-1}{\Rightarrow} \operatorname{Gamma}\left(\alpha^{*}{ }_{0 e k}, \beta^{*}{ }_{0 e k}\right)
$$

$$
\left[\Lambda_{k} \mid \psi_{e k}\right] \stackrel{D}{\Rightarrow} N\left[\Lambda_{0 k}, \psi_{e k} \mathrm{H}_{\mathrm{oyk}}\right]
$$

Where $\alpha_{0 e k}, \beta_{0 e k}, \alpha^{*}{ }_{0 e k}, \beta^{*}{ }_{0 e k}$ and the element of $\Lambda_{0 k}$ and $\mathrm{H}_{\text {oyk }}$ is the hyperparameters and $\mathrm{H}_{\text {oyk }}$ is the matrix definite positive. Conjugate prior distribution from $\Phi^{-1}$ is follow Wishart distribution with q dimension and be define $\Phi^{-1} \sim W_{q}\left[R_{0}, \rho_{0}\right]$ or equivalent with $\Phi \sim I W_{q}\left[R^{*}{ }_{0}, \rho_{0}\right]$ (2.4)

Where $W_{q}\left[R_{0}, \rho_{0}\right]$ is Wishart distribution q dimension with $\rho_{0}$ and matrix definite positive $R_{0}$ as hyperparameters while $I W_{q}\left[R^{*}{ }_{0}, \rho_{0}\right]$ is inverse from Wishart distribution with $\rho_{0}$ and matrix definite positive $R_{0}$ as hyperparameters.

\section{MCMC Application with Gibbs Sampling}

In this research, MCMC application with Gibbs Sampling is done to get the estimation of the posterior distribution on each of the unknown parameters including latent variables. To get the required characteristics of the posterior distribution of observation sufficient. For that, raised a number of observations such that the resulting empirical distribution approaches the actual distribution.

An example for a SEM model with $Y=\left(y_{1} \ldots y_{n}\right)$ is the matrix of data observation, $\Omega=$ $\left(\omega_{1} \ldots \omega_{n}\right)$ is the matrix of latent variable, and $\theta$ is the vector matrix which consist of unknown parameter are $\Lambda, \Psi, \Phi$. The stages of Gibbs Sampling in raising the posterior distribution is as follows:

1. Take an initiation $\Omega^{(j)}, \Lambda^{(\mathrm{j})}, \Psi_{\varepsilon}^{(j)}, \Phi^{(j)}$

2. Generating value $\Omega^{(j+1)}$ dari $p\left(\Omega \mid \Psi_{\varepsilon}^{(j)}, \Lambda^{(j)}, \Phi^{(\mathrm{j})}, \mathrm{Y}\right)$

3. Generating value $\Psi_{\varepsilon}^{(j+1)}$ dari $p\left(\Psi_{\varepsilon} \mid \Omega^{(j+1)}, \Lambda^{(j)}, \Phi^{(\mathrm{j})}, \mathrm{Y}\right)$

4. Generating value $\Lambda^{(j+1)}$ dari $p\left(\Lambda \mid \Omega^{(j+1)}, \Psi_{\varepsilon}^{(j+1)}, \Phi^{(j)}, \mathrm{Y}\right)$

5. Generating value $\Phi^{(j+1)} \operatorname{dari} p\left(\Phi \mid \Omega^{(j+1)}, \Psi_{\varepsilon}^{(j+1)}, \Lambda^{(j+1)}, \mathrm{Y}\right)$ 


\section{Posterior Distribution}

Concept of probability distribution with Gibbs Sampling in Bayesian SEM applying the parameters are $\theta=\left(\theta_{1}, \ldots, \theta_{\mathrm{a}}\right)$ is $\left(\Lambda, \Phi, \Psi_{\varepsilon}\right)$. As for the set of latent variables $\Omega$ where $\Omega=$ $\left(\Omega_{1}, \ldots, \Omega_{b}\right)$ a set of latent variables $\left(\Omega_{1}, \Omega_{2}\right)$, with $\Omega_{1}$ is a set of endogenous latent variable and $\Omega_{2}$ is a set of exogenous latent variable. As for the members of each set $\Omega_{1}$ and $\Omega_{2}$ can be written by $\omega_{\mathrm{i}}$. Iterations are performed in the algorithm Gibbs Sampler used by probability distribution $p\left(\Omega \mid \Psi_{\varepsilon}, \Lambda, \Phi, \mathrm{Y}\right)$ with $p\left(\Omega \mid \Psi_{\varepsilon}, \Lambda, \Phi, \mathrm{Y}\right)=p(\Omega \mid \theta, \mathrm{Y})$ and the equation is based on the definition of the conditional distribution of random vectors $\mathrm{y}_{\mathrm{i}}$ and $\omega_{\mathrm{i}}$, provided that $i=1, \ldots, n$ and $\omega_{\mathrm{i}}$ is free (mutually independent) and $\mathrm{y}_{\mathrm{i}}$ is free of $\left(\omega_{\mathrm{i}}, \theta\right)$, will be obtained equation (Lee,2007):

$$
\boldsymbol{p}(\Omega \mid \theta, \mathrm{Y})=\prod_{\mathrm{i}=1}^{\mathrm{n}} p\left(\omega_{\mathrm{i}} \mid \mathrm{y}_{\mathrm{i}}, \theta\right) \propto \prod_{\mathrm{i}=1}^{\mathrm{n}} p\left(\omega_{\mathrm{i}} \mid \theta\right) \boldsymbol{p}\left(\mathrm{y}_{\mathrm{i}} \mid \omega_{\mathrm{i}}, \theta\right)
$$

Probability distribution $\omega_{\mathrm{i}}$ is known with $\theta$ and $\mathrm{y}_{\mathrm{i}}$ conditional $\left(\omega_{\mathrm{i}}, \theta\right)$ follow normal distribution $N(0, \Phi)$ and $N\left(\Lambda \omega_{\mathrm{i}}, \Psi_{\varepsilon}\right)$. Thus, distribution $\omega_{\mathrm{i}}$ conditional $\left(\mathrm{y}_{\mathrm{i}}, \theta\right)$ is:

$$
\left(\omega_{\mathrm{i}} \mid \mathrm{y}_{\mathrm{i}}, \theta\right) \sim \mathrm{N}\left[\left(\Phi^{-1}+\Lambda^{\mathrm{T}} \Psi_{\varepsilon}^{-1} \Lambda\right)^{-1} \Lambda^{\mathrm{T}} \Psi_{\varepsilon}^{-1} \mathrm{y}_{\mathrm{i}}, \quad\left(\Phi^{-1}+\Lambda^{T} \Psi_{\varepsilon}^{-1} \Lambda\right)^{-1}\right]
$$

Thus, the conditional distribution $\Omega$ with $(\mathrm{Y}, \theta)$ is known can be compute based on the equation (2.5) and (2.6). Posterior analysis of conditional distribution where $\theta$ with the provision of $(\mathrm{Y}, \Omega)$ proportional to $p(\theta) p(\mathrm{Y}, \Omega \mid \theta)$. Model $\mathrm{y}_{\mathrm{i}}=\Lambda \omega_{\mathrm{i}}+\varepsilon_{\mathrm{i}}$ is known with $\Omega$ is the result of regression model of $y_{i}$ and $\Omega$ only depend of $\Lambda$ and $\Psi_{\varepsilon}$ while $\Phi$ only involving $\omega_{i}$ distribution. So it is known that the prior distribution $\left(\Lambda, \Psi_{\varepsilon}\right)$ and $\Phi$ is independent and can be written by:

$$
p(\theta)=p\left(\Lambda, \Phi, \Psi_{\varepsilon}\right)=p\left(\Lambda, \Psi_{\varepsilon}\right) p(\Phi)
$$

Conditional distribution $Y$ which is given $\Omega$ only depend on $\Lambda$ and $\Psi_{\varepsilon}$, while $\Omega$ distribution is depend on $\Phi$. Based on these case, can be conclude that:

$$
\begin{aligned}
p\left(\Lambda, \Psi_{\varepsilon}, \Phi \mid \mathrm{Y}, \Omega\right) & =p(\theta \mid \mathrm{Y}, \Omega) \propto p(\mathrm{Y}, \Omega \mid \theta) p(\theta) \\
& =p(\mathrm{Y} \mid \theta, \Omega) p(\Omega \mid \theta) p(\theta) \\
& =p(\mathrm{Y} \mid \theta, \Omega) p(\Omega \mid \theta) p\left(\Lambda, \Psi_{\varepsilon}\right) p(\Phi) \\
& =\left[p\left(\mathrm{Y} \mid \Lambda, \Psi_{\varepsilon}, \Omega\right) p\left(\Lambda, \Psi_{\varepsilon}\right)\right][p(\Omega \mid \Phi) p(\Phi)]
\end{aligned}
$$

Prior join distribution is used in prior distribution of $\left(\Lambda, \Psi_{\varepsilon}\right)$ and $\Phi$ can be explain with the illustration if element $\psi_{\varepsilon k}$ is a diagonal element from $\Psi_{\varepsilon}$ and $\Lambda_{\mathrm{k}}^{\mathrm{T}}$ is the k-row from $\Lambda$. So it can be written:

$$
\begin{gathered}
\psi_{\varepsilon k}^{-1} \sim \operatorname{Gamma}\left(\alpha_{0 e k}, \beta_{0 e k}\right) \\
\left(\Lambda_{k} \mid \psi_{\varepsilon k}\right) \sim N\left(\Lambda_{0 e k}, \psi_{\varepsilon k} \mathrm{H}_{o y k}\right) \\
\Phi^{-1} \sim W_{q}\left(\mathrm{R}_{0}, \rho_{0}\right)
\end{gathered}
$$

To get $p(\Phi \mid \mathrm{Y}, \Omega)$ based on the equation (2.8) with $\omega_{\mathrm{i}}$ is free, then obtained a conditional distribution $p(\Phi \mid \mathrm{Y}, \Omega)$ as follows:

$$
p(\Phi \mid \mathrm{Y}, \Omega) \propto p(\Phi) \prod_{\mathrm{i}=1}^{\mathrm{n}} p\left(\omega_{\mathrm{i}} \mid \Phi\right)
$$

Based on prior distribution of $\Phi^{-1}$ in the equation (2.11) can be conclude that $\Phi$ is follow Invers Wishart distribution with q dimension: $\Phi \sim I W_{q}\left(\mathrm{R}_{0}{ }^{-1}, \rho_{0}\right)$. Based on $\omega_{\mathrm{i}}$ distribution with conditional $\Phi$ is $N(0, \Phi)$ then the resulting:

so that,

$$
p(\Phi \mid \mathrm{Y}, \Omega) \propto|\Phi|^{-\left(\mathrm{n}+\rho_{0}+\mathrm{q}+1\right)} / 2 \exp \left(-\frac{1}{2} \operatorname{tr}\left[\Phi^{-1}\left(\Omega \Omega^{\mathrm{T}}+\mathrm{R}_{0}{ }^{-1}\right)\right]\right)
$$

$$
(\Phi \mid \mathrm{Y}, \Omega) \sim \operatorname{IW}_{\mathrm{q}}\left[\left(\Omega \Omega^{\mathrm{T}}+\mathrm{R}_{0}^{-1}, \mathrm{n}+\rho_{0}\right)\right]
$$

Likelihood function Is known from $Y$ is (Lee, 2007): 


$$
p\left(\mathrm{Y} \mid \Lambda, \Psi_{\delta}, \Omega\right) \propto\left|\Psi_{\delta}\right|^{-n / 2} \exp \left[-\frac{1}{2} \sum_{i=1}^{n}\left(y_{i}-\Lambda_{\omega \mathrm{i}}\right)^{T} \Psi_{\delta}^{-1}\left(y_{i}-\Lambda_{\omega \mathrm{i}}\right)\right]
$$

Based on likelihood and join prior from $\Lambda_{\omega \mathrm{k}}$ and $v_{\delta k}$ then posterior distribution of $\left(\Lambda_{\omega \mathrm{k}}, v_{\delta \mathrm{k}}\right)$ with given $\mathrm{Y}, \Omega$ is (Lee, 2007):

$$
\begin{aligned}
& \left(v_{\delta \mathrm{k}} \mid \mathrm{Y}, \Omega\right) \sim \operatorname{Gamma}\left(\frac{n}{2}+\alpha_{0 \delta k}, \beta_{\delta k}\right) \\
& \left(\Lambda_{\omega k} \mid Y, \Omega, v_{\delta \mathrm{k}}\right) \sim N\left(\mathrm{a}_{\omega k}, \psi_{\delta k}{ }^{-1} \mathrm{~A}_{\omega k}\right)
\end{aligned}
$$

\section{Parameter Significance Test}

Significance testing parameters on Bayesian method is done by using credible interval which generated by the predictive posterior distribution of Bayesian MCMC approach (Ntzoufras 2009). Credible interval is the interval region or area of the posterior distribution opportunities.

The parameter value on Bayesian methods indicated by the mean value obtained from the average value of the resurrection of the posterior distribution. 95\% credible interval indicated by the lower limit percentiles of $2.5 \%$ and the upper limit percentiles $97.5 \%$ of the value of the resurrection of the posterior distribution. Here is a hypothesis that is used to test the significance of the parameters in the Bayesian SEM methods:

1. $H_{0}: \gamma_{i j}=0$; there is no influence of exogenous variables on the endogenous variables

$H_{1}: \gamma_{i j} \neq 0$; there is the influence of exogenous variables on the endogenous variables

2. $H_{0}: \beta_{i j}=0$; there is no influence of endogenous variables on the endogenous variables

$H_{1}: \beta_{i j} \neq 0$; there is the influence of endogenous variables on the endogenous variables

The acceptance or rejection of based on the presence or absence of zero value in a credible interval on each parameter. Parameter is said to be significant (reject $H_{0}$ )) if credible interval does not contain the zero value and means that there are significant predictor variables on the response variable. Conversely, a parameter is said to be not significant (accept $H_{0}$ )) if credible interval includes zero value means there is no influence on the response variable predictor variables.

\section{Research Method}

Data that used in this study are primary data obtained from interviews with employees FNI Statistics in Malang which totaled 15 people on Leadership Styles, Job Satisfaction and Organizational Commitment well as interviews with corporate leaders regarding employee performance.

the following steps:

Analysis of structural equation modeling (SEM) using a Bayesian approach with 


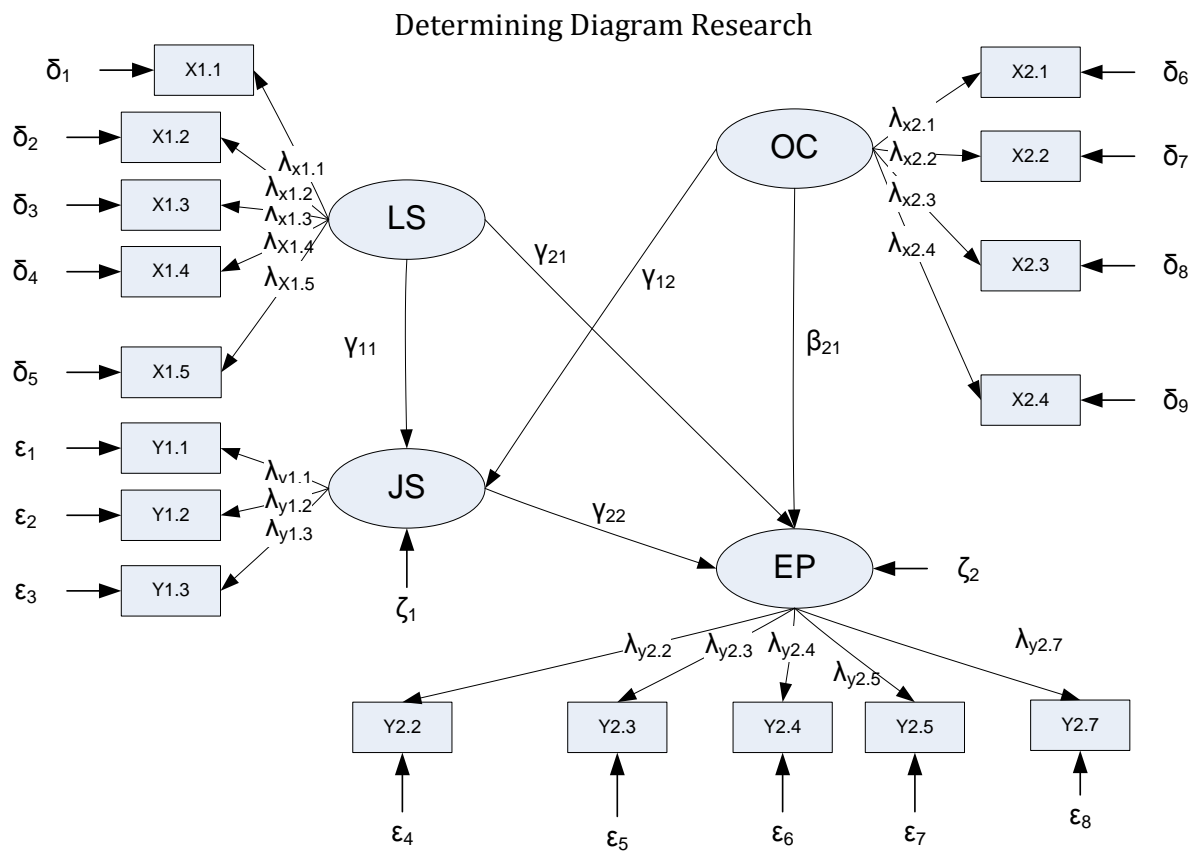

a. Determine parameter model

$\mathrm{x}$ : vector indicator for exogenous latent variable

$\mathrm{y} \quad$ : vector indicator for endogenous latent variable

$\Omega$ : matrix of exogenous and endogenous latent variable

Furthermore, there will be estimating the parameters in the model are unknown, namely $\theta$ consisting of:

$\Phi$ : covariance matrix of $\xi$ (exogenous latent variable $\xi_{1}$ : Leadership Style, $\xi_{2}$ : Organizational Commitment)

$\Psi$ : covariance matrix of $\zeta$ (measurement error of endogenous latent variable Job Satisfaction $\left(\zeta_{1}\right)$ and Employee Performance $\left.\left(\zeta_{2}\right)\right)$

$\Lambda$ : matrix of factor loading from exogenous and endogenous indicator

$\Gamma$ : matrix coefficient of relationship between exogenous to endogenous latent variables

B : matrix coefficient of relationship between endogenous to endogenous latent variables

b. Prior Choice

Prior used in this study refers to Lee (2007) is a conjugate prior distribution

c. Calculations posterior Bayesian SEM

d. MCMC Application with Gibbs Sampling to get the estimation of the posterior distribution.

e. Parameter Significance Test

Significance testing parameters on Bayesian method is done by using credible interval.

f. Parameter Accuracy Test

The accuracy test of the parameters is done by seeing MC error value where the smaller $\mathrm{MC}$ error or getting close to zero mean that parameter estimation value is better.

\section{RESULTS AND DISCUSSION}

\section{Prior Distribution}

Hyperparameters value on each prior determined using a type of conjugate prior distribution, and pseudo informative priors. Determination of the proper prior analysis will produce a more accurate and precise prediction. Hiperparameter any prior structure is presented in Table 4.1:

Table 4.1. Hyperparameters and Distribution Prior Used

\begin{tabular}{|c|c|}
\hline No & Parameters Distribution \\
\hline 1 & $\Theta_{\delta} \sim$ Invers Gamma $(9,8)$ \\
\hline
\end{tabular}




\begin{tabular}{|c|l|}
\hline No & \multicolumn{1}{c|}{ Parameters Distribution } \\
\hline 2 & $\Theta_{\varepsilon} \sim$ Invers Gamma $(9,8)$ \\
\hline 3 & $\Theta_{\eta} \sim$ Invers Gamma $(9,8)$ \\
\hline 5 & {$\left[\Lambda_{x} \mid \theta_{\delta}\right] \sim \operatorname{Normal}\left(0.393, \theta_{\delta}\right)$} \\
\hline 6 & {$\left[\Lambda_{y} \mid \theta_{\varepsilon}\right] \sim \operatorname{Normal}\left(0.393, \theta_{\varepsilon}\right)$} \\
\hline 7 & {$\left[\gamma_{1.1} \mid \psi\right] \sim \operatorname{Normal}(0.326,4 \psi)$} \\
\hline 8 & {$\left[\gamma_{1.2} \mid \psi\right] \sim \operatorname{Normal}(0.380,4 \psi)$} \\
\hline 9 & {$\left[\gamma_{2.1} \mid \psi\right] \sim \operatorname{Normal}(0.138,4 \psi)$} \\
\hline 10 & {$\left[\gamma_{2.2} \mid \psi\right] \sim \operatorname{Normal}(0.348,4 \psi)$} \\
\hline 11 & {$\left[\beta_{2.1} \mid \psi\right] \sim \operatorname{Normal}(0.679,10 \psi)$} \\
\hline 12 & $\psi \sim$ Invers Gamma $(9,8)$ \\
\hline
\end{tabular}

\section{Significance Testing Parameters and Building Model}

In Structural Equation Modeling (SEM), significance testing carried out on the model parameter measurement model and structural model. In the measurement model, significance testing was conducted to determine whether each of the significant indicators measure the latent variable or not. While the structural model, the parameter significance testing was conducted to determine whether there is influence between exogenous variables on endogenous variables or between variables endogen itself.

Parameter estimation using SEM method with the Bayesian approach is done with the help of WinBugs14 program. Summary predictive value of each parameter models and their significance testing parameters are presented in Table 4.2 and is graphically shown in Figure 4.1.

Table 4.2. Summary of Parameter Estimation Values and Significance

\begin{tabular}{|c|c|c|c|c|l|}
\hline Parameter & Mean & SD & Percentile 2.5\% & Percentile 97.5\% & Summary \\
\hline$\lambda_{x 1.1}$ & 1.000 & - & - & - & Significant \\
\hline$\lambda_{x 1.2}$ & 0.623 & 0.146 & 0.346 & 0.923 & Significant \\
\hline$\lambda_{x 1.3}$ & 0.890 & 0.194 & 0.538 & 1.308 & Significant \\
\hline$\lambda_{x 1.4}$ & 0.688 & 0.152 & 0.408 & 0.999 & Significant \\
\hline$\lambda_{x 1.5}$ & 0.721 & 0.158 & 0.426 & 1.047 & Significant \\
\hline$\lambda_{x 2.1}$ & 1.000 & - & - & - & Significant \\
\hline$\lambda_{x 2.2}$ & 0.734 & 0.163 & 0.431 & 1.074 & Significant \\
\hline$\lambda_{x 2.3}$ & 0.803 & 0.176 & 0.475 & 1.173 & Significant \\
\hline$\lambda_{x 2.4}$ & 0.723 & 0.163 & 0.418 & 1.060 & Significant \\
\hline$\lambda_{y 1.1}$ & 1.000 & - & - & - & Significant \\
\hline$\lambda_{y 1.2}$ & 0.632 & 0.158 & 0.344 & 0.964 & Significant \\
\hline$\lambda_{y 1.3}$ & 0.826 & 0.188 & 0.487 & 1.214 & Significant \\
\hline$\lambda_{y 2.2}$ & 1.000 & - & - & - & Significant \\
\hline$\lambda_{y 2.3}$ & 0.743 & 0.163 & 0.4505 & 1.094 & Significant \\
\hline$\lambda_{y 2.4}$ & 0.633 & 0.146 & 0.3657 & 0.9428 & Significant \\
\hline$\lambda_{y 2.5}$ & 0.739 & 0.156 & 0.4559 & 1.069 & Significant \\
\hline
\end{tabular}




\begin{tabular}{|c|c|c|c|c|c|}
\hline Parameter & Mean & SD & Percentile 2.5\% & Percentile 97.5\% & Summary \\
\hline$\lambda_{y 2.7}$ & 0.634 & 0.144 & 0.3727 & 0.9391 & Significant \\
\hline$\gamma_{1.1}$ & 0.440 & 0.216 & 0.02218 & 0.8674 & Significant \\
\hline$\gamma_{1.2}$ & 0.510 & 0.225 & 0.07161 & 0.9622 & Significant \\
\hline$\gamma_{2.1}$ & 0.185 & 0.239 & -0.2801 & 0.6511 & Not Significant \\
\hline$\gamma_{2.2}$ & 0.384 & 0.252 & -0.1086 & 0.8775 & Not Significant \\
\hline$\beta_{2.1}$ & 0.676 & 0.171 & 0.337 & 1.012 & Significant \\
\hline
\end{tabular}

Based on the results presented in Table 4.2 and Figure 4.1 is known that the measurement model, all significant indicators to measure each of the latent variables. While the structural model, it is known that of the five parameters tested, there are three significant parameters that $\gamma_{1.1}, \gamma_{1.2}$ and $\beta_{2.1}$. It can be concluded that there are significant differences between the variables of Leadership Style and Organizational Commitment toward Job Satisfaction directly as well as a significant difference between Job Satisfaction on Employee Performance. As for the influence of Leadership Style and variable Organizational Commitment on Employee Performance directly declared insignificant.

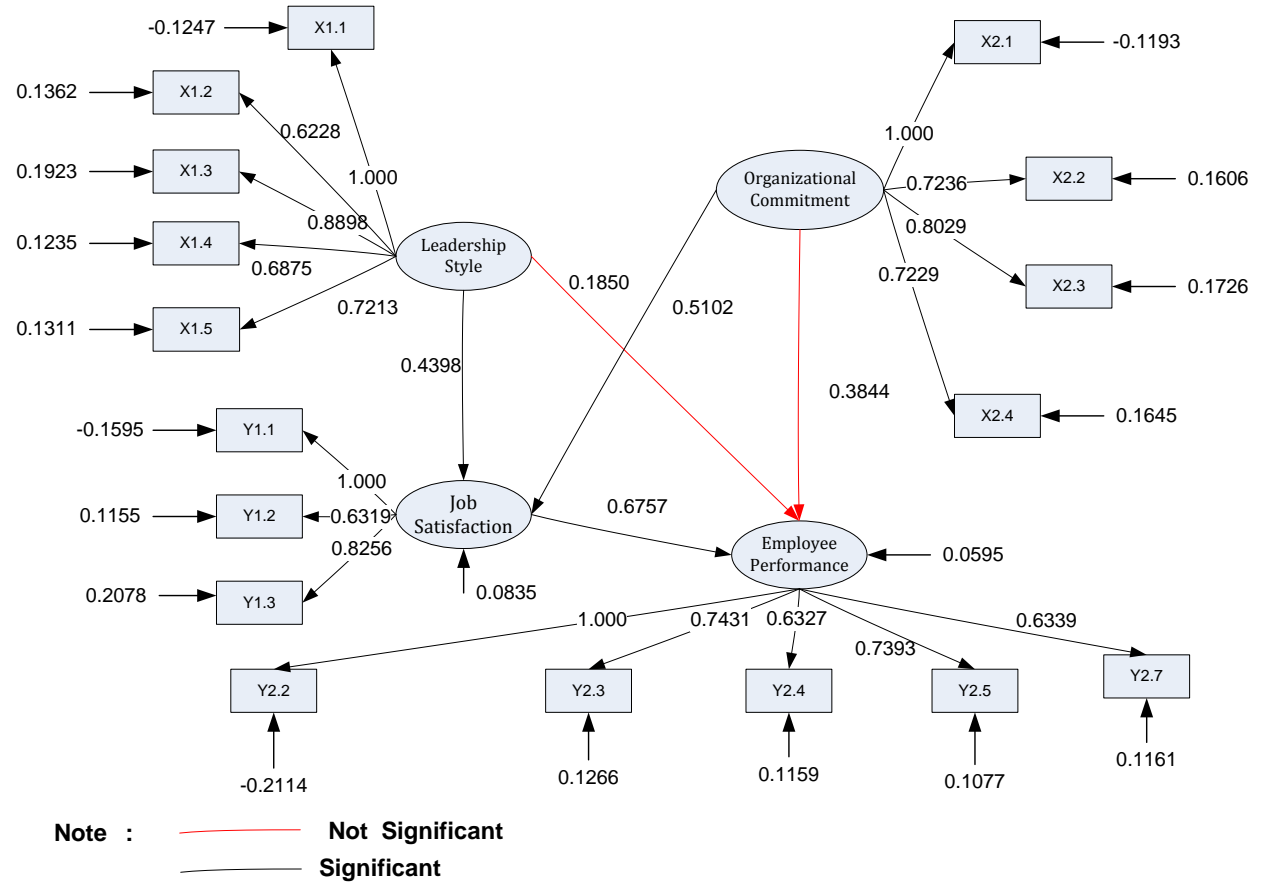

Gambar 4.1. Full Model Structural Equation Modeling

\section{Parameter Estimation Test}

One way to check the accuracy of parameter estimation in Bayesian SEM is to look at the MC error is generated, where the smaller the value MC error or getting close to zero then the better parameter estimation results. Error MC value for each parameter can be seen in Table 4.3:

Table 4.3. MC Error Value of Each Parameter

\begin{tabular}{|c|c|c|c|}
\hline Parameter & MC Error & Parameter & MC Error \\
\hline$\lambda_{x 1.2}$ & 0,002327 & $\lambda_{y 2.3}$ & 0,003308 \\
\hline$\lambda_{x 1.3}$ & 0,003417 & $\lambda_{y 2.4}$ & 0,002648 \\
\hline$\lambda_{x 1.4}$ & 0.002139 & $\lambda_{y 2.5}$ & 0.002527 \\
\hline
\end{tabular}




\begin{tabular}{|c|c|c|c|}
\hline Parameter & MC Error & Parameter & MC Error \\
\hline$\lambda_{x 1.5}$ & 0.002136 & $\lambda_{y 2.7}$ & 0.002352 \\
\hline$\lambda_{x 2.2}$ & 0.002271 & $\gamma_{1.1}$ & 0.004573 \\
\hline$\lambda_{x 2.3}$ & 0.002907 & $\gamma_{1.2}$ & 0.00446 \\
\hline$\lambda_{x 2.4}$ & 0.002294 & $\gamma_{2.1}$ & 0.00494 \\
\hline$\lambda_{y 1.2}$ & 0.002345 & $\gamma_{2.2}$ & 0.005634 \\
\hline$\lambda_{y 1.3}$ & 0.00339 & $\beta_{2.1}$ & 0.002884 \\
\hline
\end{tabular}

It is seen that the MC error of all parameters on the structural equation model is very small or approaching closer 0 (zero) value, so the results of estimation parameters generated a good result parameter estimation.

\section{CONCLUSION}

Based on the analysis and discussion, it can be concluded as follows:

1. Model of leadership style and organizational commitment to job satisfaction and employee performance using the estimation method parameters Structural Equation Modeling (SEM) through a Bayesian approach mathematically is Job Satisfaction $=0.4398$ Leadership Style + 0.5102 Organizational Commitment +0.0835 and Employee Performance $=0.1850$ Leadership Style +0.3844 Commitments organizations + Job Satisfaction $0.6757+0.0595$.

2. In the measurement model, all significant indicators to measure latent variables respectively. While the structural model, it was concluded that the five parameters tested, there are three significant parameters that $\gamma_{1.1}, \gamma_{1.2}$ and $\beta_{2.1}$. That there are a significant difference between the variables of Leadership Style and Organizational Commitment toward Job Satisfaction directly as well as a significant difference between Job Satisfaction on Employee Performance. As for the influence of Leadership Style and variable Organizational Commitment on Employee Performance directly declared insignificant.

\section{REFERENCE}

[1] I. Ntzoufras, Bayesian modeling in WinBugs. Hoboken, NJ, USA: John Wiley \& Sons, Inc, 2009, pp. --.

[2] S.-Y. Lee, Structural equation modeling: A Bayesian approach, vol. 711, John Wiley \& Sons, 2007, pp. --.

[3] L. Kogan, "Small-sample inference and bootstrap," Small, vol. 1, pp. 2--, 2010.

[4] J. F. Hair, W. C. Black, B. J. Babin, R. E. Anderson and R. L. Tatham, Multivariate data analysis, vol. 6, Pearson Prentice Hall Upper Saddle River, NJ, 2006, pp. --.

[5] I. Ghozali, "Model Persamaan Struktural: Konsep dan aplikasi dengan program AMOS ver. 16.0," Semarang, Indonesia: Badan Penerbit Universitas Diponegoro, pp. --, 2004.

[6] Arrizal, "Pemimpin Gaya Kepemimpinan Transaksional Mencapai Sukses Melalui Manajemen Sumber Daya Manusia," Jurnal Kajian Bisnis Sekolah Tinggi Ilmu Ekonomi Widya Wiwaha, no. 22, 2001. 